\section{Microembolic events during carotid stenting and surgery}

Alessia Di Girolamo, ${ }^{1}$ Debora Maruca, ${ }^{1}$ Veronica Picone, ${ }^{1}$ Camilla Gossetti, ${ }^{2}$ Alessandra Giglio, ${ }^{1}$ Bruno Gossetti ${ }^{1}$

${ }^{1}$ Vascular Surgery Department, La Sapienza University; ${ }^{2}$ Università Pontificia Salesiana (UPS), Roma, Italy

\section{Background}

The aim of this study was to assess the prevalence, quality and clinical relevance of microembolism in two hundred unselected patients submitted to carotid endarterectomy (CEA) in 104 cases and carotid stenting (CAS) in 96 cases, for hemodynamic stenosis $(>70 \%)$ of carotid bifurcations in the last three years.

\section{Methods}

High-resolution colour-flow mapping, transcranial doppler (TCD), cerebral computed tomography or magnetic resonance (MRI) and four psychometric tests were carried-out in the preoperative study in all patients. ${ }^{1-3}$ The CEA was performed under loco-regional anesthesia in $81.7 \%$, and Pruitt-Inahara shunt was used in $4.8 \%$; CAS procedure was performed in local anesthesia, using three different stents and distal filter protection devices without pre-dilatation, in $100 \%$. TCD monitoring was used to evaluate the presence and the number of microembolic events (MES) and to investi- gate the effectiveness of filter devices. ${ }^{4}$ Brain diffusion-weighted MRI was obtained within $48 \mathrm{~h}$ to detect new ischemic lesions. Psychometric tests were repeated at the discharge and after three months to evaluate cognitive faculties.

\section{Results}

During follow-up no death procedurerelated and 3 regressive minor strokes occurred; a cranic nerve lesion occurred in 4 patients submitted to CEA. TCD monitoring showed MES in 77 CEA and in 96 CAS. In 10 patients submitted to CAS repeated microemboli occurred during postoperative TCD control. A mean $70 \%$ reduction of MES was detected for the time in which the cerebral protection system was working. Postoperative DWI detected new focal ischemic lesions in 43 patients. Cognitive capability worsened in 20 patients (33 after CASs and 5 after CEA).

\section{Conclusions}

Mortality and morbidity rates of patients submitted to CAS are superimposed to results obtained by CEA. A great number of MES are recorded during surgery and above all during endovascular procedures by TCD. MES due to CAS are reduced by filter protection devices, but the cognitive faculties in a great number of asymptomatic patients may worsen.
Correspondence: Alessia Di Girolamo, Vascular Surgery Department, La Sapienza University, Roma, Italy.

E-mail: alessia.digirolamo@hotmail.it

Key words: Neurovascular diseases; meeting.

Conference presentation: $9^{\text {th }}$ Annual Meeting of the International Society of Neurovascular Disease (ISNVD), May 30 $30^{\text {th }}-31^{\text {st }}, 2019$, Ferrara, Italy

This work is licensed under a Creative Commons Attribution 4.0 License (by-nc 4.0).

(C) Copyright: the Author(s), 2019

Licensee PAGEPress, Italy

Veins and Lymphatics 2019; 8:8439

doi:10.4081/vl.2019.8439

\section{References}

1. Gossetti B, Gattuso R, Irace L, et al. Embolism to the brain during carotid stenting and surgery. Acta Chir Belg 2007;107:151-4.

2. Cosottini M, Michelassi MC, Puglioli $\mathrm{M}$, et al. Silent cerebral ischemia detected with diffusion-weighted imaging in patients treated with protected and unprotected carotid artery stenting. Stroke 2005;36:2389-93.

3. Paraskevas KI, Lazaridis C, Andrews $\mathrm{CM}$, et al. Comparison of cognitive function after carotid artery stenting versus carotid endarterectomy. Eur J Vasc Endovasc Surg 2014;47:221-31.

4. Gattuso R, Martinelli O, Alunno A, et al. Carotid stenting and transcranial Doppler monitoring: indications for carotid stenosis treatment. Vasc Endovascular Surg 2010;44:535-8. 